\title{
Differences or fundamental differences?
}

\author{
JOSJE VERHAGEN \& SARAH SCHIMKE*
}

\section{Introduction}

In his paper, Meisel discusses the differences between (bilingual) L1 ((2)L1), child L2 (cL2), and adult L2 (aL2) acquisition. He claims that both types of L2 acquisition are fundamentally different from (monolingual as well as bilingual) L1 acquisition. He argues that these fundamental differences are due to neuronal maturation and that they concern in particular the acquisition of morphosyntax. Meisel presents both neurological and linguistic evidence suggesting that the age of approximately 3;7 till 4 years is critical such that children who acquire a language after the age of acquisition (AoA) of 4 should in general be classified as cL2 learners, whereas children that start learning one (or several) languages before the AoA of 4 are expected to behave like L1 acquirers.

More specifically, Meisel postulates that maturational changes in the course of childhood explain why L1 and L2 acquisition proceed in different ways. He reviews neuroimaging studies that show that L2 learners process syntactically deviant sentences differently from native speakers (Weber-Fox \& Neville 1999). The results of these studies suggest that L2 learners show a more diffuse spatial distribution of activation patterns as well as increased activation in the right hemisphere. According to Weber-Fox \& Neville (1999), the critical age ranges from which on these changes appear lie around the age of four and the age of seven. Meisel takes this as evidence that there are qualitative changes in the acquisition process around these two age ranges.

To further pinpoint the areas of grammar where L2 acquisition might be fundamentally different from L1, Meisel considers linguistic evidence

* The authors wish to thank Wolfgang Klein for his valuable comments and suggestions, Christine Dimroth for helpful discussions and Steffi Winkler for making her results available. Both authors contributed equally to this comment. 
in the domain of morphosyntax, namely inflectional morphology and gender agreement. Based on earlier proposals made by Towell \& Hawkins (1994) and Smith \& Tsimpli (1995), Meisel argues that maturation affects parameterized domains of grammar. More precisely, he assumes that the uninterpretable features of functional categories become inaccessible or 'progressively resistant to resetting' during L2 acquisition. Hence, fundamental differences are especially expected between L1 and L2 (AoA > 4) in those areas of grammar that reflect parameterized choices.

In the following, we do not want to argue against the claim that (2)L1, cL2 and aL2 acquisition involve different processes. However, it seems to us that the more specific claim that fundamental differences, in the sense assumed by Meisel, can be observed in the acquisition of morphosyntax between L1 and L2 (AoA > 4) is premature. In our discussion, we will concentrate on linguistic evidence without further discussing the results from neuroimaging studies put forward by Meisel. Although interesting, it seems to us that the available neuroimaging data are not solid enough to allow for conclusions about the possible differences between L1, cL2 and aL2. Apart from the fact that only a handful of studies have appeared, the evidence is problematic due to the lack of a concrete connection between the neural activation patterns and specific areas of grammar. As Meisel points out himself, it is "not possible to outline a developmental schedule based on neuro-physiological evidence, indicating which aspects of grammar will be affected by such changes at what point of development" (section 2.1, paragraph 4).

In the remainder of this comment, we will therefore concentrate on one of the two linguistic areas used by Meisel for characterizing language acquisition processes at different ages: the acquisition of verbal morphology and its relation to verb placement in negated sentences. This area seems particularly well suited to detecting fundamental differences between acquisition processes. First, the acquisition of verbal morphology and verb placement has been intensively studied in both L1 and L2 acquisition (cf. Pierce 1989, Verrips \& Weissenborn 1992 for L1; Grondin \& White 1996, Haznedar \& Schwartz 1997, Dimroth 2008 for cL2; Meisel 1997, Lardiere 1998, Prévost \& White 1999 for aL2). This large amount of evidence should make it possible to decide whether L1 and aL2 are indeed fundamentally different in this domain and whether cL2 (AoA > 4) patterns with aL2 rather than L1. Second, an analysis of verb morphology and verb placement allows for a separate investigation into morphology and syntax: whereas the acquisition of specific markings on the verb is a morphological task, the placement of the verb is clearly a syntactic process. It is commonly accepted that the relation 
between verbal morphology and verb placement involves a parameterized option of UG, and many of the above-cited studies take this assumption as their starting point. If, as suggested by Meisel, fundamental differences between different acquisition processes should in particular be reflected in those areas of grammar which involve parameterized choices, such differences should be detectable in studies on verb morphology and verb placement. This is much less clear-cut in the second area which Meisel draws on - the acquisition of gender agreement. As Meisel himself says, it is difficult here to tear apart the syntactic process of gender concord from the lexically-based process of gender assignment. It is not clear whether this is a good candidate for a parameterized change.

In our review of studies on the relation between verbal morphology and verb placement, we will present data for each of the three acquisition types: L1, cL2, and aL2. Three different target languages will be considered: French, German, and Dutch. The aim of the comparison is to find out whether L1 is indeed fundamentally different from both cL2 (AoA $>4$ ) and aL2, as claimed by Meisel. In particular, looking at the same phenomenon in different acquisition types allows for a comparison of the variation found within each acquisition type as well as the variation found between acquisition types. If Meisel's predictions are correct, the variation within one acquisition type should be marginal, whereas the variation between acquisition types, in particular between $\mathrm{L} 1$ on the one hand and cL2 and aL2 on the other hand, should be substantial. Based on the idea that L2 learners have problems with parameter (re)setting, a fundamental difference is predicted for the placement of non-finite verbs in particular. Meisel states that L2 learners allow non-finite verbs to occur in a position preceding negation, whereas L1 learners only use finite verbs in this position. Thus, he considers the occurrence of nonfinite verbs in a position preceding negation "an unambiguous feature of L2 acquisition" (section 3.2., paragraph 3).

Based on our review of studies (including our own), we will show that first of all, the three acquisition types are surprisingly similar to each other in the domain investigated. In fact, there is no evidence that nonfinite verbs can appear in raised position in L2 acquisition only. This, however, does not mean that there is no variation between different learners. Rather, variation is found within the three types of acquisition as well as across types. Based on these findings, we believe that the claim that there is a qualitative, fundamental change in the acquisition process around the age of four is unwarranted. The available evidence points exactly into the opposite. 


\section{Reviewing the literature on finiteness and negation}

The data in Table 1 to 3 present an overview of earlier data from acquisition studies on finiteness and negation in French, German, and Dutch. The data show how often finite and non-finite forms occurred in a raised and non-raised position with respect to negation in L1, cL2 and aL2. In all three target languages finite verbs raise to the left of the negator, while non-finite verbs remain to its right. Importantly, this is assumed to be due to a verb-raising parameter, which is set early in the acquisition process. As put by Meisel: "It is well known [...] that the parameters responsible for the V2 effect are set very early, probably around or even before age 2;0" (section 2.2., paragraph 11). Meisel does not spell out what these parameters are. This makes an evaluation somewhat difficult. But for the sake of the discussion, let us assume that there is indeed a parameter, which accounts for the raising of finite verbs above negation. This predicts that all finite verbs should precede the negator and all nonfinite verbs follow the negator in L1, whereas such a relation should be less clear in cL2 and aL2.

For all studies presented, the numbers indicate the occurrence of finite and non-finite forms preceding and following the negator pas in French (except for the data from Verrips \& Weissenborn (1992) who also included plus, jamais and rien), nicht in German, and niet in Dutch. In case the authors specified the clause types investigated, only declarative main clauses were considered. In most studies, "finite" forms refer to forms that are not infinitives or past participles (i. e., finite does not mean 'correctly agreeing'), whereas "non-finite" refers to infinitival and past participle forms. ${ }^{1}$ As far as we could conclude from the description in these studies, non-finite forms that are homophonous with finite forms were counted as "non-finite" when they appeared in a non-finite context and as "finite" when they appeared in the correct finite context for this form. That is, forms ending on -en in German and Dutch, which can be infinitives or plural forms, were counted as "finite" only when they co-occurred with a plural subject and appeared in a raised position. To avoid this ambiguity, the data collected by ourselves are restricted to third person singular contexts. ${ }^{2}$ The tables also provide information about the number of learners investigated in each study, their L1, their age of acquisition (AoA), and age of testing (AoT). When the same data

1. The only exception is Parodi (2000), in which finite means 'correctly agreeing', and nonfinite either refers to infinitival forms, past participles, or non-agreeing finite forms.

2. Although the other studies in general include plural contexts, it should be noted that these are very rare in children's speech: for example, in the data provided by Winkler (2006), there was only one clear plural context. Similar observations have been reported by Poeppel \& Wexler (1993). 
Table 1: Overview of finite/non-finite forms in negated contexts for L1, child L2, and adult L2 French

\begin{tabular}{|c|c|c|c|c|c|c|c|c|c|}
\hline & \multirow[t]{2}{*}{ Study } & \multicolumn{4}{|c|}{ Learner characteristics } & \multicolumn{2}{|c|}{$\mathrm{V}-\mathrm{NEG}$} & \multicolumn{2}{|c|}{ NEG - V } \\
\hline & & $\mathrm{N}$ & L1 & AoA & AoT & + fin & - fin & + fin & - fin \\
\hline $\mathrm{L} 1$ & $\begin{array}{l}\text { Pierce (1989) } \\
\text { Verrips \& Weissen } \\
\text { born (1992) }\end{array}$ & $\begin{array}{l}4 \\
2\end{array}$ & $\begin{array}{l}- \\
-\end{array}$ & - & $\begin{array}{l}1 ; 8-2 ; 3 \\
1 ; 5-2 ; 2\end{array}$ & $\begin{array}{l}216 \\
204\end{array}$ & $\begin{array}{l}2 \\
1\end{array}$ & $\begin{array}{l}9 \\
7\end{array}$ & $\begin{array}{r}122 \\
21\end{array}$ \\
\hline cL2 & $\begin{array}{l}\text { Grondin \& White } \\
\text { (1996) }\end{array}$ & 2 & English & $4 ; 5,4 ; 9$ & $5 ; 4,5 ; 8$ & 770 & 2 & 18 & 36 \\
\hline aL2 & $\begin{array}{l}\text { Prévost \& White } \\
\text { (1999) } \\
\text { Prévost (2004) } \\
\text { Schimke (2009) }\end{array}$ & $\begin{array}{r}2 \\
21 \\
43\end{array}$ & $\begin{array}{l}\text { Arabic } \\
\text { English } \\
\text { Turkish }\end{array}$ & $\begin{array}{l}19,34 \\
\text { Not reported } \\
16 ; 6-40 ; 6\end{array}$ & $\begin{array}{l}20 ; 2-23 ; 5 \\
35-37 ; 8 \\
18-54 \\
(\text { mean } 29 ; 4) \\
18-49\end{array}$ & $\begin{array}{l}217 \\
251 \\
111\end{array}$ & $\begin{array}{r}10 \\
3 \\
6\end{array}$ & $\begin{array}{l}8 \\
7 \\
8\end{array}$ & $\begin{array}{r}25 \\
1\end{array}$ \\
\hline & & & & (mean 26) & (mean $34 ; 1)$ & & & & \\
\hline
\end{tabular}

Table 2: Overview of finite/non-finite forms in negated contexts for L1, child L2, and adult L2 German ${ }^{4}$

\begin{tabular}{|c|c|c|c|c|c|c|c|c|c|}
\hline & \multirow[t]{2}{*}{ Study } & \multicolumn{4}{|c|}{ Learner characteristics } & \multicolumn{2}{|c|}{$\mathrm{V}-\mathrm{NEG}$} & \multicolumn{2}{|c|}{$N E G-V$} \\
\hline & & $\mathrm{N}$ & L1 & AoA & AoT & + fin & - fin & + fin & - fin \\
\hline \multirow[t]{2}{*}{ L1 } & Schaner-Wolles & 1 & - & - & $2 ; 2-2 ; 9$ & 96 & 22 & 14 & 15 \\
\hline & Winkler (2006) & 4 & - & - & $1 ; 11-3 ; 06$ & 115 & 1 & 4 & 20 \\
\hline \multirow[t]{2}{*}{ cL2 } & Haberzettl (2005) & 2 & Russian & $7 ; 7,8 ; 5$ & $\begin{array}{l}7 ; 8-9 ; 5 \\
8 ; 6-11 ; 1\end{array}$ & 64 & 0 & 6 & 13 \\
\hline & Dimroth (2008) & 2 & Russian & $8 ; 7,14 ; 2$ & $8 ; 8-9 ; 2 ;$ & 444 & 0 & 3 & 1 \\
\hline \multirow[t]{3}{*}{ aL2 } & $\begin{array}{l}\text { Prévost \& White } \\
(1999)\end{array}$ & 2 & Spanish & 17,22 & $\begin{array}{l}17 ; 3-19 ; 5 \\
22: 3-24: 4\end{array}$ & 172 & 18 & 10 & 19 \\
\hline & Parodi (2000) & 3 & $\begin{array}{l}\text { Italian, } \\
\text { Spanish }\end{array}$ & $16,16,23$ & $16,17,23$ & 102 & 3 & 7 & 15 \\
\hline & Schimke (2009) & 47 & Turkish & $\begin{array}{l}16-42 \\
\text { (mean 24) }\end{array}$ & $\begin{array}{l}17-51 \\
(\text { mean } 33 ; 1)\end{array}$ & 70 & 4 & 23 & 55 \\
\hline
\end{tabular}

were analyzed in different studies, the data are presented in the table only once. ${ }^{3}$

3. For example, the data of Philippe in Verrips \& Weissenborn (1992) are not reported because the same data are analyzed by Pierce (1989). Likewise, the data from Meisel (1997) are not reported because they overlap with the data in Parodi (2000) and Prévost \& White $(1999,2000)$.

4. Unfortunately, no quantitative data on finiteness and negation in German are given in Clahsen \& Penke (1992), Meisel \& Müller (1992), Verrips \& Weissenborn (1992), Behrens (1993), Poeppel \& Wexler (1993) and Lasser (1997). 
Table 3: Overview of finite/non-finite forms in negated contexts for L1, child L2, and adult L2 Dutch

\begin{tabular}{|c|c|c|c|c|c|c|c|c|c|}
\hline & \multirow[t]{2}{*}{ Study } & \multicolumn{4}{|c|}{ Learner characteristics } & \multicolumn{2}{|c|}{$\mathrm{V}-\mathrm{NEG}$} & \multicolumn{2}{|c|}{$\mathrm{NEG}-\mathrm{V}$} \\
\hline & & $\mathrm{N}$ & L1 & AoA & AoT & + fin & - fin & + fin & - fin \\
\hline $\begin{array}{l}\text { L1 } \\
2 \mathrm{~L} 1\end{array}$ & Wijnen $^{5}(199$ & 1 & $\begin{array}{l}- \\
-\end{array}$ & $\begin{array}{l}- \\
-\end{array}$ & $2 ; 7-3 ; 10$ & 404 & 4 & 6 & 47 \\
\hline cL2 & $\begin{array}{l}\text { Aarssen (1996) } \\
\& \text { Bos (1997) }\end{array}$ & 23 & $\begin{array}{l}\text { Arabic, } \\
\text { Turkish }\end{array}$ & $4^{7}$ & 4 & 39 & 0 & 0 & 5 \\
\hline $\mathrm{aL} 2$ & Verhagen (2009) & 57 & Arabic & $\begin{array}{l}18-39 \\
(\text { mean } 24 ; 7)\end{array}$ & $\begin{array}{l}19-42 \\
(\text { mean } 28)\end{array}$ & 278 & 5 & 22 & 47 \\
\hline & Verhagen (2009) & 46 & Turkish & $\begin{array}{l}15-32 \\
(\text { mean } 22 ; 10)\end{array}$ & $\begin{array}{l}19-42 \\
(\text { mean 28) }\end{array}$ & 123 & 10 & 29 & 135 \\
\hline
\end{tabular}

Let us first check Meisel's assumption against these data: Is it the case that non-finite verbs in second position are an unambiguous feature of L2-acquisition? As to L1, there are two clear results. First, the data suggest that this generalisation does not hold: in all studies on L1 acquisition summarized above, non-finite verbs occasionally appear in a finite position. Second, the data also show considerable variability across studies: whereas the L1 learners of French in Pierce (1989) and Verrips \& Weissenborn (1992) barely move non-finite verbs to the left of negation, the L1 child in Schaner-Wolles (1995/96) does so rather frequently: 22 out of 118 verbs in raised position are non-finite in the data from this child. We will come back to this variability below.

For aL2 acquisition, the data indeed show that non-finite verbs are incidentally found in raised position and, in fact, more frequently appear in this position than in L1 acquisition. However, the number of nonfinite forms in raised position is very low in all studies: percentages range between $1.2 \%$ and $7.5 \%$. Comparing $\mathrm{L} 1$ and aL2 to cL2 acquisition, then, it seems that non-finite forms in raised position are rarest in the data from the cL2 learners. Except for two cases in the data from the cL2 learners of French investigated by Grondin and White (1996), there are no occurrences of non-finite verbs in raised position in the data from

5. The data from De Houwer, Wijnen, Aarssen and Bos were taken from the corpora in the childes language database (available at: http://childes.psy.cmu.edu/data/). For publications on these data, see De Houwer (1990), Wijnen (1995), Aarssen (1996), and Bos (1997).

6. The child investigated by De Houwer simultaneously acquired English and Dutch and therefore constitutes a case of (2)L1. This makes these data particularly comparable to the ones presented by Meisel.

7. These children were born in the Netherlands, but only started to have regular contact with the Dutch language from age of 4 . 
this population. Clearly, these findings speak against Meisel's suggestion that cL2 learners would have difficulties in setting the verb-raising parameter or in realizing inflectional morphology, and should therefore resemble aL2 more than cL1. Instead, the current data show that, if anything, cL2 learners are more similar to L1 than to L2 learners with respect to the placement of finite and non-finite verbs in raised position.

This is not to say, however, that there is no variation within a certain type of acquisition. Such variation is especially striking when one compares the data from the children in Winkler (2006) and "Nico" in Schaner-Wolles (1995/96): whereas the children investigated by Winkler almost never raise non-finite verbs past negation, this is a frequent pattern in Nico's data. Such variation is not found for the aL2 data presented above. However, the behaviour of the different aL2 learners is not uniform either: the data suggest that these learners have an overall preference for verb-raising or "no raising" dependent on the source and target languages at issue. More specifically, the data show that adult Turkish learners of Dutch (Verhagen 2009) produce non-finite verbs in non-raised position and finite verbs in a raised position to a similar degree. However, adult Moroccan learners with the same level of proficiency $^{8}$ show a strong preference for verbs to occur in a raised position with respect to negation. This difference suggests that the typological make-up of the source language, that is, whether or not it is a verbraising language, can influence the $\mathrm{L} 2$ acquisition process, at least when adult learners are considered. The data from the adult Turkish learners of French and German (Schimke 2009) suggest, moreover, that L2 learners with the same source language can show different preferences according to target language characteristics. Clearly, the learners of German more often place verbs in non-raised position than the learners of French. The observation that the typological properties of the source language as well as the target language may influence the acquisition process confirms earlier findings in the literature (Vainikka \& YoungScholten 1996; Schwartz \& Sprouse 1996; Meisel 1997). Meisel (1997) has noted, for example, that there are fewer instances of non-raised verbs in L2 French when compared to other target languages. Given the influence of the source language in particular, it is all the more surprising that the general pattern in the aL2 studies still is very close to the pattern found in $\mathrm{L} 1$ acquisition.

As for the third type of acquisition, cL2 acquisition, the variability found is lower than for the other two types. At least in the above-de-

8. The Moroccan and Turkish learners in this study were recruited in the same language course (A1 or A2 level according to the guidelines of the European Framework of Reference, Council of Europe, 2001). 
scribed studies, it seems that cL2 acquirers rapidly develop a preference for the target-like pattern over all other possible combinations: they rely less on non-finite forms overall and produce finite forms in a raised position in the vast majority of utterances. Further research is needed to confirm to what extent this pattern is reliable. The present data suggest that cL2 learners show this target-like behaviour from the first occurrences of negated utterances onwards: the data collection for the studies of Haberzettl (2005) and Dimroth (2008) started almost immediately after the onset of acquisition and as such, captured the very first occurrences of verbs in learners' speech. The negated utterances included in the above table were thus the first negated utterances used by these children in verbal contexts during the recordings. Importantly, the placement of the few occurrences of non-finite forms shows that the investigated cL2 acquirers do not differ from the other types of learners in being aware of the relation between finiteness and verb placement: when they use non-finite forms, such forms typically appear to the right of the negator. In short, it seems that these learners are sensitive to the relation between finiteness marking and verb placement, but differ from the other learner groups in showing a strong preference for finite verb forms from early onwards.

Summing up, an overview of studies on (2)L1, cL2 and aL2 suggests that the three types of acquisition differ in the type and amount of variability found in each type of acquisition. At the same time, the data also show striking similarities between the three acquisition types. First, a strong contingency between finiteness marking and verb placement is found in all studies, irrespective of type of acquisition. Second, there are exceptions to the main pattern in all cases: finite verbs can occur in non raised position and non-finite verbs can appear in raised position. What is crucial, then, is that the variation across acquisition types does not seem remarkably higher than the variation within acquisition types. This seems difficult to reconcile with the "fundamental differences" view on language acquisition proposed by Meisel. While there might be differences between L1 and L2 acquisition, there seem to be equally important differences between different groups of learners within one acquisition type. Importantly, this does not only hold for aL2 acquisition, but also for L1 acquisition. It seems to us that the most parsimonious explanation of the data therefore is to assume that at least some processes are shared across acquisition types.

Further studies are needed to find out which factors can influence the acquisition process leading to different paths taken by different learners, and which of these factors are related to AoA. The differences in the type and amount of variability between the three types of acquirers suggest that certain acquisition processes do change as a function of AoA. 
However, we do not think that the empirical evidence for the idea that there is a fundamental change around the age of 4, affecting morphosyntax in particular, warrants any firm conclusion yet. If this idea was correct, one would have found clearer differences between L1 learners on the one hand and cL2 and aL2 learners, on the other, than became apparent when comparing data from different studies in the acquisition literature.

\section{References}

Aarssen, Jeroen (1996). Relating events in two languages: Acquisition of cohesive devices by Turkish-Dutch bilingual children at school age. (Studies in Multilingualism 2) Tilburg: Tilburg University Press.

Behrens, Heike (1993). Temporal reference in German child language: Form and function in early verb use. Unpublished Ph.D. dissertation, University of Amsterdam.

Bos, Petra (1997). Development of bilingualism: A study of school-age Moroccan children in the Netherlands. Tilburg: Tilburg University Press.

Clahsen, Harald \& Martina Penke (1992). The acquisition of agreement morphology and its syntactic consequences: New evidence on German child language from the Simonecorpus. In The acquisition of verb placement, Jürgen M. Meisel (ed.), 181-223. Dordrecht: Kluwer.

De Houwer, Annick (1990). The acquisition of two languages from birth: A case study. Cambridge: Cambridge University Press.

Dimroth, Christine (2008). Age effects on the process of L2 Acquisition? Evidence from the acquisition of negation and finiteness in L2 German. Language Learning 58: 117-150.

Grondin, Nathalie \& Lydia White (1996). Functional categories in child L2 acquisition of French. Language Acquisition 5: 1-34.

Haberzettl, Stefanie (2005). Der Erwerb der Verbstellungsregeln in der Zweitsprache Deutsch durch Kinder mit russischer und türkischer Muttersprache. Tübingen: Max Niemeyer.

Haznedar, Belma \& Bonnie D. Schwartz (1997). Are there optional infinitives in child L2 acquisition? In Proceedings of the 21st annual Boston University conference on language development, Elizabeth Hughes, Mary Hughes \& Annabel Greenhill (eds.), 257-268. Somerville, MA: Cascadilla Press.

Lardiere, Donna (1998). Dissociating syntax from morphology in a divergent L2 end-state grammar. Second Language Research 14: 359-375.

Lasser, Ingeborg (1997). Finiteness in adult and child language. Ph.D. dissertation. New York: Cuny Graduate Center.

Meisel, Jürgen M. \& Natascha Müller (1992). Finiteness and verb placement in early child grammars: Evidence from simultaneous acquisition of French and German bilinguals. In The acquisition of verb placement, Jürgen M. Meisel (ed.), 109-138. Dordrecht: Kluwer.

Meisel, Jürgen M. (1997). The acquisition of the syntax of negation in French and German: Contrasting first and second language development, Second Language Research 13: $227-263$.

Parodi, Teresa (2000). Finiteness and verb placement in second language acquisition. Second Language Research 16: 355-381.

Pierce, Amy E. (1989). On the emergence of syntax: a cross-linguistic study. Unpublished Ph.D. Dissertation: MIT.

Poeppel, David \& Kenneth Wexler (1993). The full competence hypothesis of clause structure in early German. Language 69: 1-33. 
Prévost, Philippe (2004). Morphological variation in early adult second language French: a cross-sectional study. In EUROSLA Yearbook 2004, Susan Foster-Cohen, Mike Sharwood-Smith, Antonella Sorace \& Mirs Ota (eds.), 147-175. Amsterdam: Benjamins.

Prévost, Philippe \& Lydia White (1999). Accounting for morphological variation in second language acquisition: Truncation or missing surface inflection? In The acquisition of syntax, Marc-Ariel Friedmann \& Luigi Rizzi (eds.), 202-235. London: Longman.

Schaner-Wolles, Chris (1995/96). The acquisition of negation in a verb second language: From 'anything goes' to 'rien ne va plus'. Wiener Linguistische Gazette 53-54: 87-119.

Schimke, Sarah (2009). The acquisition of finiteness by Turkish learners of German and Turkish learners of French: Investigating knowledge about forms and functions in production and comprehension. Ph.D. dissertation: Max-Planck-Institute for Psycholinguistics, Nijmegen.

Schwartz, Bonnie D. \& Rex A. Sprouse (1996). L2 cognitive states and the full transfer/full access model. Second Language Research 12: 40-72.

Smith, Neil \& Ianthi-Maria Tsimpli (1995). The mind of a savant. Language learning and modularity. Oxford: Blackwell.

Towell, Richard \& Roger Hawkins (1994). Approaches to second language acquisition. Clevedon: Multingual Matters.

Vainikka, Anne \& Martha Young-Scholten (1996). Gradual development of L2 phrase structure. Second Language Research 12: 7-39.

Verhagen, Josje (2009). Finiteness in Dutch as a second language. Ph.D. dissertation: Vrije Universiteit Amsterdam \& Max-Planck-Institute for Psycholinguistics, Nijmegen.

Verrips, Maaike \& Jürgen Weissenborn (1992). Routes to verb placement in early child German and French: The independence of finiteness and agreement. In The acquisition of verb placement, Jürgen M. Meisel (ed.), 283-331. Dordrecht: Kluwer.

Weber-Fox, Christine M. \& Hellen J. Neville (1999). Functional neural subsystems are differentially affected by delays in second language immersion. ERP and behavioural evidence in bilinguals. In Second language acquisition and the critical period hypothesis, David Birdsong (ed.), 23-38. Mahwah, NJ: Erlbaum.

Wijnen, Frank (1995). Clause structure develops. In Papers from the Dutch-German colloquium on language acquisition, Maaike Verrips \& Frank Wijnen (eds.), 203-216. Amsterdam: Institute for General Linguistics.

Winkler, Steffi (2006). Finiteness in first and second language acquisition. Annual Report MPI for Psycholinguistics, Nijmegen, 106-107.

Josje.Verhagen@mpi.nl Max-Planck-Institute Nijmegen sarah.schimke@mpi.nl Max-Planck-Institute Nijmegen 